\title{
Contribution of safe motherhood solidarity groups in using and accessing maternity services during a period of armed conflict
}

\author{
Richard Bitwe Mihanda ${ }^{1,2^{*}}$, Jean Robert Likofata ${ }^{3}$, Gwendolyn J. Lusi ${ }^{3}$ \\ ${ }^{1}$ Mentor Research, Hospital Management, HEAL Africa, Goma, DR Congo \\ ${ }^{2}$ University of Goma, Goma, DR Congo; *Corresponding Author: richard.bitwe@gmail.com \\ ${ }^{3}$ Development Projects, HEAL Africa, Goma, DR Congo
}

Received 9 January 2013; revised 1 May 2013; accepted 7 June 2013

Copyright (C) 2013 Richard Bitwe Mihanda et al. This is an open access article distributed under the Creative Commons Attribution License, which permits unrestricted use, distribution, and reproduction in any medium, provided the original work is properly cited.

\section{ABSTRACT}

This report presents the results of a study on Reproductive Health done in North Kivu in September 2009. It was conducted by HEAL Africa, in partnership with the Provisional Division of Health, and financed by the University of Ottawa, Canada/CRDI with technical assistance from Western Cape University of South Africa. The study was conducted in the health zones of $\mathrm{Bi}$ rambizo and Kayna within the framework of the central office. The focus of the report is on one aspect of Reproductive Health-Low Risk Maternity. This study was conducted in rural areas given that Reproductive Health indicators are much weaker when compared with urban areas, according to EDS RDC, 2007 [1]. This study emphasizes the following points: General characteristics of the participants in the study, and the utilization and accessibility of maternity services in rural areas in conflict situations. The formula SPSS 12.0.1 was used to facilitate data analysis in the study. This study comes at a point in time when its relevance to HEAL Africa's work will assist HEAL and its partners in determining the focus of interventions done in health zones in order to improve maternal and neonatal health. HEAL Africa firstly stepped into a Safe Motherhood pilot project in June 2006 for 9 months in the Masisi zone, then in 2007 in the Birambizo and Kayna health zones. In November 2007, HEAL expanded into Walikale and in October 2008, into Kirotshe, Binza, and Lubero. The intervention kit consists of reinforcing the capacity of existing health facilities, training tra- ditional midwives who serve as a link between the community and the health structures, the provision of sanitary equipment, medical essentials and community mobilization was done through local leaders about health and reproduction, and organizing women of reproductive age in solidarity groups (SG) to generate maternity insurance. The community approach "Solidarity Groups for Maternity Insurance" constitutes the spine of HEAL Africa within the support it provides in Reproductive Health. The principal idea is to educate and train communities on how to use the MMR services that are available in their community, and to remove financial barriers to accessing health services. The 4 pillars that comprise the Safe Motherhood program are: family planning, prenatal care, safe assisted delivery and essential obstetric care. These four strategic measures are integral in assuring primary health care and equality for women. This study evaluates this approach, keeping in mind local strategies and their effects on improving the utilization and accessibility of reproductive health services.

Keywords: Safe Motherhood; Solidarity Group; Usage of Maternity Services; Accessibility of Maternity Services; Reproductive Health; Maternal Health

\section{INTRODUCTION}

Within the multitude of problems, interventions and possible causal relationships affect maternal mortality and morbidity in rural Africa, this study will attempt to 
evaluate the value to a community of a safe motherhood program in North Kivu, Democratic Republic of Congo, which addresses the social determinants of health problems and identifies the particular contributions that solidarity groups make to maternity care, safe birth, and obstetric care.

Eastern Congo has experienced war without end since 1996. The effects of the war on health are seen in the destruction and pillage of health infrastructures, the flight of qualified personnel, the continual displacement of people living in abject poverty, illness, malnutrition, injuries, the interruption of immunization programs and reproductive health, and in the spread of communicable diseases, in particular sexually transmitted diseases and HIV, often spread through sexual violence.

Despite the theoretical full health coverage through 515 health zones, the DRC has the worst maternity mortality rates in the world. Worldwide, the maternal mortality average is $140-200 / 100,000$ live births-however, in DRC, it is 1298/100,000 live births [2].

Within this context, HEAL Africa's Safe Motherhood Program addresses the social and structural factors that hinder maternal health and safe birth practices. The HEAL safe motherhood program is conducted using a two-pronged approach: medical and community. In terms of the medical approach, SM works in collaboration with health structures such as health centers and general reference hospitals. SM helps these institutions with capacity building and trainings for staff in reducing maternal mortality, as well as equipping health centers and remodeling maternity centers.

As peer of information, Heal Africa set up a safe motherhood experimental project in June 2006 within Masisi Health Zone for 9 months, and then in May 2007 in Birambizo, Binza and Lubero Health Zones.

The intervention packages include: capacity building of health workers, training of traditional birth attendants who serve as a bridge between the community and health structures, support in health equipments and essential medicines, community mobilizations through local leaders regarding health reproduction, and taking care of women in procreation age gathered in solidarity groups for maternity insurance.

Our interventions consist of supporting solidarity groups with rotative micro-credit aiming to reinforce maternity insurance for uppermost percentage of women to get supported after delivery. For each solidarity $\$ 500$ (five hundred American dollars) are given and each person should be reimbursed \$2 each month to reinforce maternity insurance for women and have more babies outfits for those who cannot afford them after delivery.

Solidarity groups also have to farm together and after harvesting they sell the crops to reinforce maternity insurance. With the rotative micro-credit, women deal with local income generation grant to support their families.

Regarding the medical approach, solidarity groups work with health structures such as health centers and general reference hospitals. Activities which are carried out include: Capacities improvement of medical staff regarding safe motherhood, to equipping health structures, and renovating maternity centers.

The community facet includes the following: training of TBAs in SM techniques, training of agents who will carry out mobilization sessions in the community, and training of local leaders (religious and tribal ones).

The community is also impacted through socio-economic assistance such as: training in IGAs, creation of Solidarity Groups to implement maternity insurance groups, rotation credits to lower poverty within the members' household.

This various pronged approach attempts to address all factors that prevent or inhibit women from seeking maternal care in an established clinic or medical institution.

In this context, does the implementation of HEAL Africa's Safe Motherhood program in communities significantly impact maternal health?

\section{MATERIALS AND METHODS}

\subsection{Study Case Locations}

This study was conducted in the rural health zones of Birambizo and Kayna, in the province of North Kivu. The Birambizo health zone has a population of 379,338 inhabitants within an area of $1080 \mathrm{~km}^{2}$, therefore a population density of 351 inhabitants per $\mathrm{km}^{2}$. There are 32 health areas with their own health center and 356 villages. Regarding health facilities, there are 39 state health centers, three health centers of religious affiliation, 18 health posts, a general reference hospital (GRH), and a hospital of religious affiliation.

In the health zone of Kayna, the total population is estimated to be 318,464 habitants within a $2570 \mathrm{~km}^{2}$ area; population density of 124 inhabitants per $\mathrm{km}^{2}$. There are 20 health aires with their own health centers, and 107 villages. This zone has 16 health centers, four health centers of reference, 42 health posts, and a general reference hospital. All health facilities are of the Congolese state. Of the four project areas, we chose these two, Birambizo, where the program has been operational for three years and Kayna, where the program will be implemented for the first time. Here is the map (Figure 1) of this region.

\subsection{Sampling and Research Methods}

To calculate the sample size for the population survey in both areas, we used Epi Info 6.04 for Windows. They administered the survey to 87 women members of solidarity groups and 87 who are not members of solidarity 


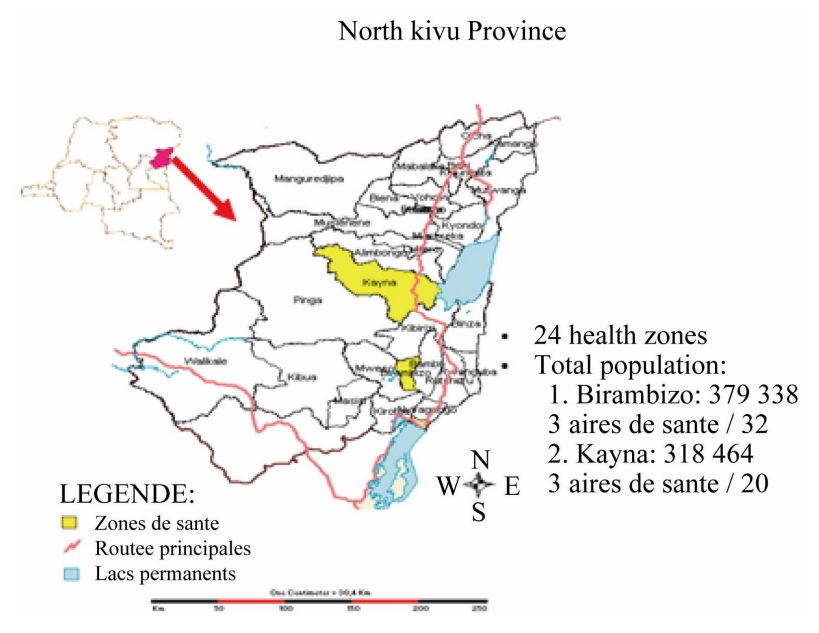

Figure 1. Map of North Kivu Province.

groups in each zone.

We held two focus groups for women in solidarity groups and two focus groups for women who are not in solidarity groups. We held two focus and discussion groups for traditional birth attendants in solidarity groups and 2 for TBAs who are not in solidarity groups. They held two focus groups for men in Nehemiah committees in areas where solidarity groups are active, and two in zones where the solidarity groups are not active.

They used the same tools for data collection in both health zones. These tools were pre-tested by the researchers. Interviewers and leaders of the target groups were recruited from the community, to avoid potential bias by using project staff. A pre-test of semi-structured interviews and focus groups was conducted in the health zone in Kirotshe with the head zone doctor, group members of the Nehemiah Committees, and women of childbearing age. The household questionnaire, another tool of this study, was tested in Bweremana and Kihindo.

Interviewers were high school graduates with knowledge of local languages. Investigators were trained in the proper administration of the questionnaire and facilitation of the focus groups. To ensure credible, reliable and transferable information, they paid attention to the following:

The research team consisted of people with experience in qualitative methods, who were able to provide adequate training for new investigators and investigators recruited from the community. They provided adequate supervision during the data collection and systematic archiving of data.

\subsection{Statistical Analysis}

Coding, thematic analysis and quantitative data analysis were supported by the best available computer program (SPSS). Data entry and analysis were performed by two or more qualified researchers on the team. The analysis will focus specifically on the context, to isolate the information transferable and not accessible from the study.

\section{RESULTS}

\subsection{Participant Characteristics}

The survey was conducted with both a qualitative and quantitative analysis. The quantitative involved a survey of 352 respondents; $40 \%$ members of SGs and $60 \%$ non-members; $48 \%$ of people surveyed in Birambizo and $52 \%$ in Kayna. The qualitative analysis consisted of semistructured interviews of stakeholders and 20 focus groups in the 2 zones, involving 2 Head Zone Doctors, 4 Supervising Nurses, women of childbearing age, members of SM SGs, women of childbearing age, non-members of SM SGs, TBA members of SM SGs.

The average age of solidarity group members is 30.8 years (SD 10.29) and of non-group members, is 35.22 (SD 8.54). Christianity is the most common religion, $98 \%$ of participants, and $74 \%$ of participants were married. The proportion of female respondents between 15 - 49 years is $93 \%$, above 50 years 6\%, 12 - 14 years 1\% (Table 1).

\subsection{Contribution of Solidarity Groups to Increased Usage of and Access to Maternity Services}

The large majority of female respondents were of childbearing age, and out of this group $45 \%$ are part of SM solidarity groups. Most women from areas where SM project is operating recognize a positive impact of the program on maternal health and on knowledge and access to information about reproductive health. Another contribution is regarding family planning, where most respondents agree on a positive impact.

This table demonstrates an important statistical association between the utilization of maternity services and membership in solidarity groups. There is also a strong association between giving birth with assistance from a health professional, the detection and treatment of obstetrical complications and belonging in a solidarity group (Table 2 ).

The next table (Table 3 ) displays a significant statistical association between accessing maternity services and maternity insurance.

Focus groups of SG members identified the impact of the SM program on access and utilization through the following statements and testimonies:

- SM has abolished the bad habit of women giving birth from their houses;

- Thanks to SM, women work together and pay maternity fees for members of the SG;

- Our wives have learned a variety of skills; they have been educated in giving birth at the hospital and seek- 
Table 1. General characteristics of survey participants.

\begin{tabular}{|c|c|c|c|c|}
\hline $\mathbf{N}=$ & SG members & $\%$ & No SG members & $\%$ \\
\hline \multicolumn{5}{|l|}{ Religion } \\
\hline Catholic & 64 & 45.1 & 95 & 46.1 \\
\hline Protestant & 78 & 54.9 & 107 & 51.9 \\
\hline Moslem & 0 & 0 & 1 & 0.5 \\
\hline Jehovah witnesses & 0 & 0 & 3 & 3 \\
\hline \multicolumn{5}{|l|}{ Education level } \\
\hline University & 2 & 1.4 & 4 & 2 \\
\hline High school & 30 & 21.3 & 18 & 9.1 \\
\hline Primary completed & 23 & 16.3 & 26 & 13.2 \\
\hline Primary not completed & 29 & 20.6 & 31 & 15.7 \\
\hline literate & 1 & 0.7 & 5 & 2.5 \\
\hline Illiterate & 56 & 39.7 & 113 & 57.4 \\
\hline \multicolumn{5}{|l|}{ Etat civil } \\
\hline Single & 11 & 7.7 & 26 & 12.6 \\
\hline Engaged & 4 & 2.8 & 6 & 2.9 \\
\hline Married & 113 & 79.6 & 145 & 70.0 \\
\hline Divorced & 4 & 2.8 & 6 & 2.9 \\
\hline Widow & 10 & 7.0 & 24 & 11.6 \\
\hline \multicolumn{5}{|l|}{ Occupation } \\
\hline Farmer & 123 & 89.8 & 190 & 95.0 \\
\hline Civil employee & 4 & 2.9 & 3 & 1.5 \\
\hline School teacher & 2 & 1.5 & 1 & 0.5 \\
\hline Businessmen & 6 & 4.4 & 3 & 1.5 \\
\hline Resourceful & 2 & 1.5 & 3 & 1.5 \\
\hline \multicolumn{5}{|l|}{ Age } \\
\hline Average age & 10.29 & & 8.54 & \\
\hline Mean & 30.73 & & 35.22 & \\
\hline
\end{tabular}

Table 2. Usage of maternity services by solidarity group members.

\begin{tabular}{lccc}
\hline Comparison indicators & Solidarity group members No solidarity group members & RR & p \\
\hline Utilization & 168 & 31 & 3.71 \\
Yes & 3 & 86 & 1 \\
No & & & 0.0001 \\
Delivery with health workers & 26 & 17 & 1.96 \\
Doctor & 119 & 103 & 1.17 \\
Nurse & 13 & 1.95 & 0.0006 \\
TBA & 62 & 13 & 0.0005 \\
None & & 24 & 0.01 \\
Complicated obstetrical detection and treatment & 6 & 3 & 5.85 \\
Abortion & 8 & 10 & 2.36 \\
C-section & 14 & 3 & 11.38 \\
Hemorrhage & 5 & 11 & 1.46 \\
Threat of abortion & 60 & 34 & 0.003 \\
Others & 34 & 114 & 0.0001 \\
None & & & 0.46 \\
\hline
\end{tabular}


Table 3. Accessibility of services for usage of maternity insurance.

\begin{tabular}{|c|c|c|c|c|}
\hline Comparison indicators for maternity insurance & $\begin{array}{c}\text { Utilization maternity } \\
\text { insurance }\end{array}$ & $\begin{array}{c}\text { No utilization of } \\
\text { maternity insurance }\end{array}$ & $\mathbf{R R}$ & $\mathbf{p}$ \\
\hline \multicolumn{5}{|l|}{ Utilization } \\
\hline Yes & 154 & 134 & 1.19 & 0.0001 \\
\hline No & 5 & 30 & & \\
\hline \multicolumn{5}{|l|}{ Delivery with health workers } \\
\hline Doctor & 23 & 20 & 1.82 & 0.002 \\
\hline Nurse & 99 & 114 & 1.16 & 0.003 \\
\hline TBA & 4 & 20 & 0.92 & 0.84 \\
\hline None & 6 & 26 & 1 & \\
\hline \multicolumn{5}{|l|}{ Complications } \\
\hline Abortion & 5 & 4 & 3.97 & 0.02 \\
\hline C-section & 6 & 11 & 1.81 & 0.2 \\
\hline Hemorrhage & 12 & 5 & 6.17 & 0.0001 \\
\hline Threat of abortion & 4 & 10 & 1.41 & 0.53 \\
\hline Others & 51 & 39 & 2.19 & 0.001 \\
\hline None & 23 & 85 & 1 & \\
\hline
\end{tabular}

ing health care earlier on;

- New mothers have been educated to pursue care in the hospital even after they have delivered;

- It reduces the ratio of women who deliver at home.

SG members receive financial support through the rotating credit allowances and the AGRs. This financial support provides the means for women to afford maternal health care. Women reported that they were able to afford ante-natal care, delivery fees, and post-natal care due to the support of the SGs. Safe motherhood solidarity groups have enabled women from all social classes to access quality maternity services and pay for them. Pregnant women are starting ante-natal consultations much earlier than before. Members of SGs who give birth in the hospital have enough money to pay their bills. Safe Motherhood has therefore contributed to the leveling of economic inequities related to access of maternity services.

\subsection{Identification of Experience and Perception of the Project Stakeholders Regarding the Value of Safe Motherhood Solidarity Groups}

In terms of availability of medicine and staff, cost reduction, information knowledge, financial availability, all stakeholders appreciate the value of solidarity groups. Doctors, nurses and other health workers also report changes in health behaviors related to access and utilization. Stakeholders at Birambizo health zone reported:

Q: In general, women arrive at the hospital (regarding their pregnancy) only when there is a problem or to receive advice too?
A: 1 -Sometimes they come to the hospital after finding out that there is a risk for the pregnancy or when they are experiencing abdominal pains and feeling weak.

2-Other women, especially with teachings from the SM program, have discovered that they must not wait until they have problems to come to the hospital. It is necessary to come to the health center from conception so that we can daily keep an eye on her pregnancy and find out what problems can occur.

The director of the Kayna health zone also commented on changes in behavior regarding seeking health care as well as increased ability for women to pay for pregnancy and birth care.

Q: About the economic aspects. Does the hospital see the impact of SM on the economic aspect? For example, are the women-members of solidarity groups-able to pay better for treatments and cesarean sections?

R: Solidarity groups help significantly, though we can find people who can pay with their own funds.

Q: Can you tell a specific story of members of solidarity groups?

R: They now know that for every pregnancy, you must go to the health center even if they have gone to see a TBA. These days, even TBAs are sending pregnant women to the health center. Another thing they are informed about is cleanliness, breast feeding, and family planning.

Project stakeholders also reported positive attitudes of nurses and doctors toward the Safe Motherhood program. Stakeholders in Kayna health zone reported on the opinions of nurses, stating that nurses would like to see the program last for a long time as they are taught new mate- 
rial and are also reminded of knowledge and skills they learned in nursing school. The director reported a similar response from TBAs, who appreciate the program and the knowledge they are gaining, reflected by their presence at any training offered by SM. There they are taught new skills and they share with us their own experiences.

\subsection{Social and Environmental Change}

While breaking down financial, physical, and technical factors that hinder access and utilization through the support and financial assistance of solidarity groups, study participants also reported on the impact of the program on the social and cultural factors that influence the seeking of maternity health care.

The following statements from focus group members, both members and non-members of SGs reflect opinions on the impact of SM on communities:

- It brings change in the way of thinking of people;

- It contributes to the fraternity of people here;

- The number of members is only growing and they are working more and more;

- From SM, people are learning how to live together in union and fraternity.

Thanks to SM, there is change within families:

- There has been dialogues within families concerning family planning;

- Mothers have learned how to avoid unwanted pregnancies;

- SM has helped our community with advice on preventing maternal mortality.

Participants and community members of the SM program perceive benefits and have seen changes in their families, communities, and health status. The SM program has generated dialogue and discussion in families and communities, and people see positive results of the program on community fraternity-not just for the targeted women of childbearing age.

Members of SM program reported various motivating elements to joining, including the training the women receive on IGAs, rotating credit allowances, information on family planning, HIV, and gender, as well as literacy classes and social support. These benefits encourage membership, and also address the gamut of social aspects that contribute to poor health-addressing cultural, educational, and financial barriers in order to better equip women to make informed health decisions.

\section{DISCUSSION}

The participatory mechanism of the solidarity groups and their political capacity has been improved due to close partnerships with strong community leaders, such as religious leaders and tribal chiefs. The voice of vulnerable groups is promoted and heard through the weight of these leaders and their specific power to influence the whole community and effect change.

The access that women have to SG in communities where Safe Motherhood is operating greatly reduces the risk of maternal mortality and increases maternal and infant health. The inter-lapping effects of community mobilization, education, solidarity groups, rotating credit, and support to TBAs and health centers has successfully decreased factors that lead to women giving birth at home.

Members of solidarity groups use maternity services more than individuals who are not members of solidarity groups. They prefer to give birth within health structures and clinics, and with trained health personnel, where the detection and treatment for complications is more advanced. The increased usage of health structures for labor and delivery leading to improved detection and management of complications is better for members with maternity insurance.

Solidarity groups encourage equitable access to medical care, because there is no discrimination within the SM group membership system. The program is open to all ethnic groups and all generations, the members just divide themselves up according to reproductive age. Community empowerment occurs through the teamwork and partnership that happens within and among the groups. As the groups enable the women to pay for medical care, staff and management at clinics and hospitals are encouraged and motivated to provide better quality care.

Maternity insurance, as provided through the SM program, contributes to a reduction in maternal mortality, and in the larger picture will improve health standards for the whole community. Individual vulnerability is reduced, thanks to access to financial support and a new feeling of confidence and security that is generated by membership within an IGA (Income Generating Activities) group and the socio-economic aid this entails.

The dissemination of knowledge, trainings, and information provided by the program permits the population to obtain a more appropriate understanding of the importance of health care. As a result, changes occur in education levels, family planning habits, and cultural practices related to maternal health.

The program generates a number of environmental changes as well. For example, many traditional birth attendants who were called to home births in the past now work within health structures. The training of medical personnel (including midwives and traditional birth attendants) is also a remarkable change that has been brought by the project.

Fraternity, team work, involving leaders, and giving them a stake in how the project unfolds are integral parts of the SM program. Fostering connections and relation- 
ships with community leaders assists in achieving full community buy-in to the project, thereby laying the groundwork for change in habits and health beliefs and practices.

The participatory mechanism of the solidarity groups and their political capacity has been improved due to close partnerships with strong community leaders, such as religious leaders and tribal chiefs. The voice of vulnerable groups is promoted and heard through the weight of these leaders and their specific power to influence the whole community and effect change.

Social determinants of health are affected by the number of farmers, whose income supplements their family, helping finance education and other sectors.

\section{CONCLUSIONS}

Solidarity Groups as a way to provide maternal insurance is an effective response to increase accessibility and utilization of reproductive health services in North Kivu. Women must be involved in matters that concern their fates in order to reduce maternal mortality. There must be a good relationship between women and healthcare services, so that women seek out access knowing they will receive quality care and be supported by the community. Such a goal is not easy to achieve in Africa, because a high percentage of women are illiterate, and specialist services are inaccessible both geographically and financially. Women should be trained and informed about prevention and promotion of maternal health. The four pillars are: family planning, antenatal care, a hygienic delivery, and essential obstetrical care [3].

HEAL Africa's SM program adequately addresses these four pillars, and through the various SM interventions, is able to increase access and usage of maternity health services. Women, community members, traditional healers, and health structure staff are involved in education and awareness trainings, raising their communal consciousness of the importance of maternal health care and uniting communities. The participatory nature of the SM program, combined with the multi-faceted community approach, is an effective tool in reducing maternal risk and improving health for pregnant women and their infants.

\section{ACKNOWLEDGEMENTS}

Acknowledgements to Professors Ronald Labonté and David Sanders, Nikki Shaay, Mama Neema, and Pastor Samuel for their scientific contribution. This study was funded by the Teasdale-Corti Global Health Research Partnership Program, a collaborative health research program developed by the four founding partners of the Canadian Global Health Research Initiative-Canadian Institutes of Health Research, International Development Research Centre, Health Canada and Canadian International Development Agency-with input from the Canadian Heath Services Research Foundation.

\section{REFERENCES}

[1] Ministère du Plan \& Ministère de la Santé (2008) Enquête démographique et de Santé, République Démocratique du Congo 2007.

http://www.measuredhs.com/pubs/pdf/FR208/FR208.pdf

[2] World Health Organization (1996) Le dossier mère-enfant: Guide pour maternité sans risque.

http://apps.who.int/iris/bitstream/10665/63168/1/WHO_F HE_MSM_94.11_Rev.1_fre.pdf

[3] World Bank (2007) The World Bank annual report. http://siteresources.worldbank.org/EXTANNREP2K7/Re sources/English.pdf 